\title{
Capillary Electrophoresis (CE): a Powerful Tool to Characterize Humic Acid (HA)
}

\author{
Solange L. de Moraes* and Maria Olímpia O. Rezende \\ Instituto de Química de São Carlos, Universidade de São Paulo, CP 780, 13560-970 São Carlos-SP, Brazil
}

\begin{abstract}
Neste estudo, avaliou-se a possibilidade de eliminação das etapas de purificação envolvidas na caracterização de HA. HA de diferentes fontes foram analisados por CZE apresentando diferentes eletroferogramas. Essas diferenças observadas mostram que a caracterização do HA por CZE depende da carga e do tamanho do HA. Os resultados apresentados neste trabalho sugerem que não é necessária a purificação da amostra para a caracterização de HA por CZE. Baseados nos resultados, a CZE mostrou-se uma ferramenta promissora para caracterização de HA de diferentes origens sem a etapa de purificação da amostra.
\end{abstract}

The present study evaluates the possibility of eliminating the purification steps involved in the characterization of HA by capillary zone electrophoresis (CZE). The HAs of various sources were analyzed, showing different electropherograms by CZE, which depend on the charge and size of HA. The data suggest that the purification of the sample is not necessary to characterize HAs. Based on the results, CZE showed to be a promising tool to characterize HA of different origins without the purification step of the sample.

Keywords: humic acid, characterization, capillary zone electrophoresis

\section{Introduction}

Humic substances (HS) have an important role in the environment. They are related to the fertility of the soils, contributing to the increasing the harvest production. ${ }^{1,2}$ In soil, HS are implicated in water-holding capacity, $\mathrm{pH}$ buffering, ion exchange, binding of metal ions and hydrophobic compounds. ${ }^{3-6}$ These substances are classified into three groups, humic acids (HAs), fulvic acids (FAs) and humins, on the basis of their solubility in acidic and basic solutions. ${ }^{7-9}$

HAs present relatively high molecular mass polyelectrolytes containing aromatic, aliphatic and heterocyclic subunits. ${ }^{10}$ Their chemical structure is less known due to the origin and the natural conditions prevailing during their formation. ${ }^{11}$ The degree of ionization of these macromolecules is governed by the amount of ionized phenolic and carboxylic groups of HAs, which is a function of solution $\mathrm{pH} .^{12-14}$

As a modern analytical technique, capillary electrophoresis (CE) has become an attractive method for the characterization of molecules with high structural complexity and wide range of molecular weights, such as

*e-mail: soso@fcfrp.usp.br
HA. ${ }^{15-18}$ The CE, as a method of characterizing a variety of $\mathrm{HS}$, is suitable due to its polyelectrolyte properties, reflecting its charge-to-mass ratio. ${ }^{19-26}$ The characterization of humic compounds provides important information for the evaluation of their capacity of interaction with metal ions and different classes of organic compounds as pesticides. ${ }^{25}$ Some valuable features of this analytical technique are short analysis time, selectivity for the analytes, simple analytical procedure, and micro-quantity consumption of samples. In CZE, the introduction of samples is carried out at the anode, while the detection is realized at the cathode. Ionic species are separated based on their charge and size, which are functions of the $\mathrm{pH}$ value of the electrolyte solution. ${ }^{27}$

The aim of this work was to characterize HAs samples of different origins by CZE, considering each step of purification.

\section{Experimental}

\section{Chemicals}

All reagents used were of analytical grade acquired from Merck or Aldrich. Deionized water obtained by Millipore system was used to prepare all solutions, standards and electrolytes. 


\section{Apparatus}

CE experiments were performed on a Hewlett Packard 3D Capillary Electrophoresis equipped with a diode array detector (DAD). Uncoated fused silica capillary (50 $\mathrm{mm}$ id., $56 \mathrm{~cm}$ length from the detector, $64.5 \mathrm{~cm}$ total length) was obtained from Hewlett Packard. The samples were injected by pressure ( $50 \mathrm{mbar} \times 10 \mathrm{~s})$, and a voltage of $20 \mathrm{kV}$ was applied at a temperature of $30^{\circ} \mathrm{C}$. The signals were recorded with UV-Vis detection at $214 \mathrm{~nm}$. The mode electrophoresis used for all experiments was CZE.

Before starting the analyses or between determinations using different electrolytes, the capillary was flushed with $1 \mathrm{~mol} \mathrm{~L}^{-1} \mathrm{NaOH}$ for $5 \mathrm{~min}$, then with deionized water for $10 \mathrm{~min}$ and with the used electrolyte for $15 \mathrm{~min}$. Between each run, the capillary was flushed with water for $2 \mathrm{~min}$, followed by a flush with the running electrolyte for $3 \mathrm{~min}$.

The electrolytes utilized were $20 \mathrm{mmol} \mathrm{L}^{-1}$ borate buffer $\mathrm{pH} 9.3$.

\section{Humic acids}

The samples evaluated in this work were: HAs extracted from peat (PHA), 10-25 cm depth from Mogi-Guaçu River margin, São Paulo State, Brazil, HAs obtained from vermicompost (VHA) originated from animal manure and treated with Eisenia foetida or Lumbriculus rubellus, and a commercial HA obtained from Aldrich (AHA), lot N0 $05924 \mathrm{KN}$.

\section{Extraction and purification of the sample}

The extraction and purification of HA samples from peat and vermicompost were performed according to the International Humic Substance Society (IHSS) adapted method, ${ }^{24,28}$ based on acid and basic extractions followed by purification with successive elution through cationic and anionic resins. The collected fractions were: non-purified $\mathrm{HA}$ (fraction 1), $\mathrm{HA}$ after $\mathrm{Cl}^{-}$removal (fraction 2) and HA after purification through cationic and anionic resins (fraction 3). Each collected fraction was liofilized and stored for further analysis by CZE. Figure 1 illustrates the described procedure.

To perform CZE analyses the HA-containing solutions were prepared by dissolving $1.0 \mathrm{mg}$ of $\mathrm{HA}$ in a small volume of $0.1 \mathrm{~mol} \mathrm{~L}^{-1} \mathrm{NaOH}$ solution (approximately two drops) and diluting up to the fixed volume of $1 \mathrm{~mL}$ with deionized water (Millipore system). An ultrasonic bath was applied for 3-5 min to enhance dispersion (Branson ultrasonic).

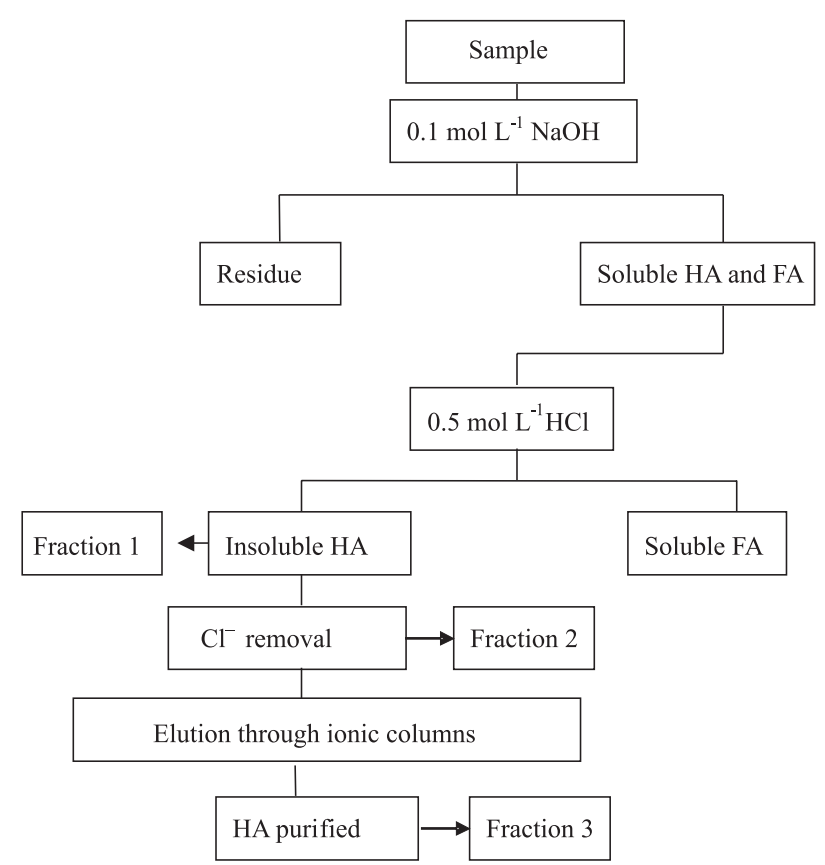

Figure 1. Scheme of the fractions of HA collected: (fraction 1) non-purified, (fraction 2) after $\mathrm{Cl}^{-}$removal, and (fraction 3) purified.

The effect of organic matter was determined through the values of ash for each fraction 1, 2 and 3 (Figure 1). The values of ash were obtained by ashing the sample at $600{ }^{\circ} \mathrm{C}$ for $5 \mathrm{~h}$.

\section{Results and Discussion}

In this work, all the purification steps involving HA samples were evaluated. Firstly, the extraction of sample with $\mathrm{NaOH}$ was performed. Next, the HA samples was flushed several times to eliminate chloride ions originated from the $\mathrm{HCl}$ solution used to separate humic and fulvic acids. Then, HA was exhaustively eluted through exchange columns to remove cations and anions present in the samples. This step is very long and depending on the sample, it may last several weeks. In this context, the possibility of working with HA without purification was investigated, considering that the distribution patterns for HA of different origins could be compared if the separation were carried out under the same conditions. Figure 2 shows the electropherograms of PHA in borate buffer considering the purification steps of the sample.

If two HA samples exhibit the same behavior in an electric field, then they should have a comparable chargeto-mass ratio and the migration time will be a distinctive criterion if the molecular weight is unknown. ${ }^{19}$ However, we tried to compare the electrophoretic behavior of different fractions of HA samples (non-purified, after $\mathrm{Cl}^{-}$removal and purified) by evaluating the migration times. 


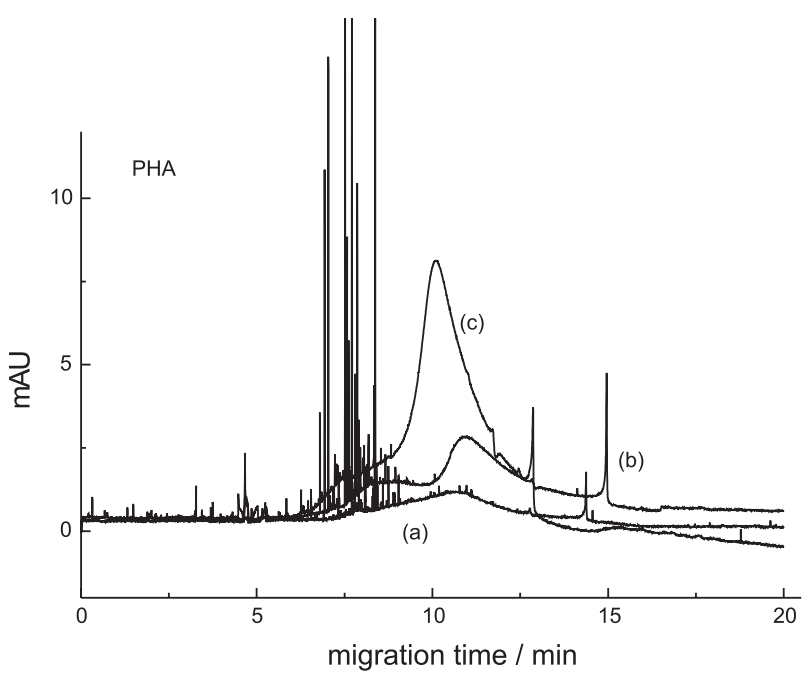

Figure 2. Electropherogram of PHA $\left(1.0 \mathrm{mg} \mathrm{mL}^{-1}\right)$ : (a) non-purified, (b) after $\mathrm{Cl}^{-}$removal (c) purified. Conditions: $20 \mathrm{mmol} \mathrm{L}^{-1}$ borate buffer $\mathrm{pH} 9.3 ; 20 \mathrm{kV}, 10 \mathrm{~s}, 214 \mathrm{~nm}$.

The degree of ionization of these macromolecules is known to be governed by the number of ionized phenolic and carboxylic groups of the humic core, which is a function of the $\mathrm{pH}$ solution. In this case, we observed superimposed peaks as an unresolved broad shoulder in all electropherograms, which is assigned to the anionic region of the HA. No individual component can be distinguished under the present experimental conditions. At pH 9.3, the negative charges carried by the analytes are maximized and the acid groups carry all the negative charges. According to several authors, ${ }^{18-26}$ this region is attributed to homogeneous "humic hump" in the anionic region with a distribution around an average electrophoretic mobility (AEM).

The shapes of the broad bands that appear for PHA are quite similar, Figure 2, but the most intense peak was attributed to the purified PHA (Figure 2c). It is reasonable to assume that for more purified samples, the number of negative charges that they carry is larger. However, it is useful to ratify that the region of interest of the eletropherogram (broad band known as "humic hump") presents basically the same behavior for the purified HA (Figure 2c), non-purified case (Figure 2a) and after $\mathrm{Cl}^{-}$ removal (Figure 2b). It is worthwhile to notice that after the $\mathrm{Cl}^{-}$removal, the "humic hump" region increased in intensity, in comparison to the non-purified sample. The same procedure was repeated for other HA samples, as shown in Figures 3 and 4.

Figure 3 presents the electropherograms obtained for purified and non-purified AHA. It is important to point out that AHA was obtained commercially and the purified AHA was made only by ionic resins. Again, the same behavior was observed in the PHA case: the broad bands are similar.
However, the most intense peak is observed in the purified sample. The broad forms of the peaks and the CE profiles are quite similar, denoting that these shapes are due to the acid groups with a similar structure.

These lower peaks of the "humic hump" of the nonpurified PHA sample can be attributed to the presence of several components, metals for instance, associated with the humic structure. In this case, the molecule of HA would not be completely dissociated, resulting in a minor amount of HA by UV detection.

Figure 4 presents the electropherograms for the VHA fractions. It is interesting to observe that after chloride removal (Figure 4b), the VHA presents almost the same profile of the "humic hump" (Figure 4c), but with a minor intensity.

We evaluated the influence of inorganic matter (ash) on each fraction analysed by CZE. Table 1 presents the ash content obtained for different HA samples.

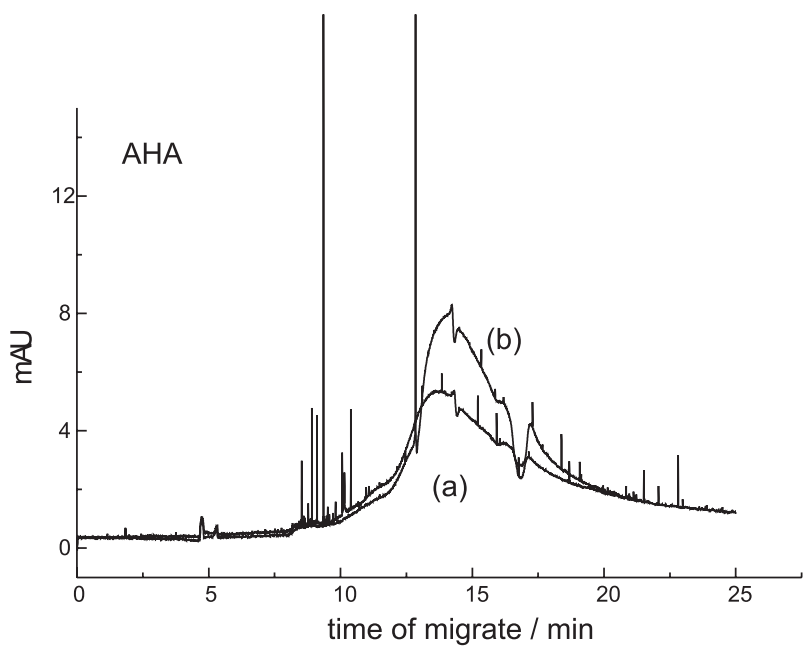

Figure 3. Electropherogram of AHA $\left(1.0 \mathrm{mg} \mathrm{mL}^{-1}\right)$ : (a) non-purified, (b) purified. Conditions: $20 \mathrm{mmol} \mathrm{L}^{-1}$ borate buffer $\mathrm{pH} 9.3 ; 20 \mathrm{kV}, 10 \mathrm{~s}$, $214 \mathrm{~nm}$.

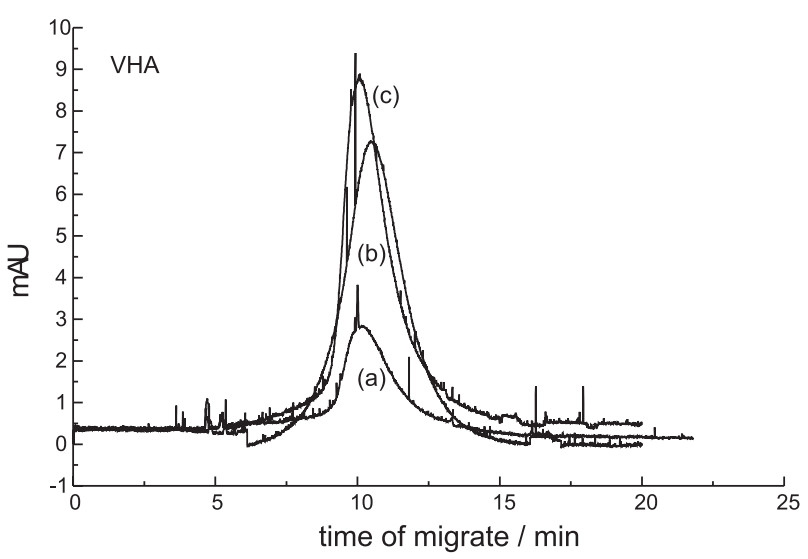

Figure 4. Electropherogram of VHA (1.0 $\left.\mathrm{mg} \mathrm{mL}^{-1}\right)$ : (a) non-purified, (b) after $\mathrm{Cl}^{-}$removal (c) purified. Conditions: $20 \mathrm{mmol} \mathrm{L}^{-1}$ borate buffer pH 9.3; $20 \mathrm{kV}, 10 \mathrm{~s}, 214 \mathrm{~nm}$. 
Table 1. Ash content obtained from different fractions of HA samples

\begin{tabular}{lccc}
\hline HA samples & \multicolumn{3}{c}{ Values of ash / (\%) } \\
\cline { 2 - 4 } & fraction 1 & fraction 2 & fraction 3 \\
\hline THA & 72.30 & 53.20 & 4.80 \\
AHA & 48.90 & & 2.60 \\
VHA & 71.20 & 42.60 & 1.40 \\
\hline
\end{tabular}

The ash values indicate the purity of the material. The lower the value, the purer the material. The values of ash (Table 1) were compared with the results obtained by CZE (Figures 2, 3 and 4). We observed that samples with a low value of ashes presented higher "humic hump" bands. It is reasonable to suppose that in the non-purified HA there are more complex groups that hamper the dissociation of the HA molecule by UV detection.

In all CZE analyses, the non-purified HA sample presents minor intensity of peaks probably due to the smaller amount of HA available with UV detection. The result is a loss of signal. This fact reinforces the possibility of eliminating the several steps of purification related to elution through the ion exchange columns, therefore various samples of HAs can be rapidly analyzed by CZE in a short time with the advantage of reducing costs and submitting the sample to fewer manipulations.

The average apparent mobility $\left(\mu_{\mathrm{ap}}, \mathrm{cm}^{2} \mathrm{Vs}^{-1}\right)$ in Table 2 was calculated for each fraction of HAs studied, according to the equation: $\left.\mu_{a p}=v / \mathrm{E}=(\mathrm{Ld} / \mathrm{tm}) / \mathrm{V} / \mathrm{Lt}\right)$, where $\mu$ is the velocity, $\mathrm{E}$ is the electric field strength, Ld is the length from the capillary to the detector, Lt is the total length of the capillary, $\mathrm{V}$ is the applied voltage and tm is the migration time.

The data of average apparent mobility as a normalized parameter permits, in principle, the comparisons between the HA fractions. These values showed that the mobility of the non-purified HA (fraction 1) is similar for the purified $\mathrm{HA}$ (fraction 3) and minor for the $\mathrm{HA}$ after $\mathrm{Cl}^{-}$removal (fraction 2), considering the same experimental conditions. As the values of mobility presented for fractions 1 and 3 are similar, the characterization of the HAs samples can be made directly in CZE after the extraction of the sample.

Table 2. Values of average apparent mobility obtained from different fractions of HA samples

\begin{tabular}{llcc}
\hline HA & $\begin{array}{c}\text { samplesvalue of average apparent mobility } /\left(\mathrm{cm}^{2} \mathrm{Vs}^{-1}\right) \\
\text { fraction 1 }\end{array}$ & fraction 2 3 \\
\hline THA & $2.96 \times 10^{-4}$ & $2.74 \times 10^{-4}$ & $2.98 \times 10^{-4}$ \\
AHA & $2.06 \times 10^{-4}$ & & $2.04 \times 10^{-4}$ \\
VHA & $2.97 \times 10^{-4}$ & $2.88 \times 10^{-4}$ & $2.95 \times 10^{-4}$ \\
\hline
\end{tabular}

\section{Characterization of humic acids by CZE}

It is well-known that the migration of analytes in CZE depends on their charge-to-mass ratio. Therefore, the characterization of HAs by CZE is due to their charge and size, which depend on the HA origin and natural condition during their formation. Since the HAs present polyelectrolyte properties, they can be easily characterized by CZE, depending on the $\mathrm{pH}$. Consequently, the choice of the separation buffer plays a key role in the interpretation of the electrophoretic patterns. It is obligatory that the very same analytical steps be followed in order to characterize different samples of HA. Considering the fraction purified for all HAs, Figures $2 c, 3 c$ and $4 c$, the shortest migration time was obtained for AHA, suggesting that the AHA possesses a major charge-to-size ration and a minor apparent mobility compared with other HAs. On the other hand, the PHA and VHA indicate an approximately similar number of dissociated groups (minor migration time), suggesting that they present similar charge-tosize ration. These characteristics are due to different charge-to-size rations and various structural properties of the individual components of HA caused by their different origin.

\section{Conclusions}

The characterization of HAs by CZE is due to their charge and size, which is a function of different structural, physical and chemical properties. The present study shows the potential of CE for the characterization of HAs of different origins, without purifying them through the ionic exchange columns. Therefore, a greater number of HA samples could be analyzed in a short time, with minor modifications in the molecular structure of the HA. According to our results, the step of extraction is sufficient to characterize HA by CZE with the advantages of rapid separation, small amounts and fewer manipulations of the samples.

\section{Acknowledgments}

The authors would like to acknowledge CNPq and FAPESP (fellowship to S. L. M., 00/02368-5), for the financial support given to this research.

\section{References}

1. Stevenson, F. J.; Humus Chemistry, Genesis: Composition, Reactions, $1^{\text {st }}$ ed., John Wiley: New York, 1982. 
2. Stevenson, F. J.; Biochemistry of the Formation of Humic Substances. Humic Chemistry, $2^{\text {nd }}$ ed.; John Wiley: New York, 1982.

3. Xing, B.; Environ. Pollut. 2001, 111, 303.

4. Janos, P.; J. Chromatogr., A 2003, 983, 1.

5. Myneni, S. C. B.; Brown, J. T.; Martinez, G. A.; Meyer-Ilse, W.; Science 1999, 286, 1335.

6. Wanner, U.; Burauel, P.; Führ, F.; Environ. Pollut. 2000, 108, 53.

7. Rosa, A. H.; Rocha, J. C.; Furlan,M.; Quim. Nova 2000, 23, 472.

8. Piccolo, A.; Conte, P.; Adv. Environ. Res. 2000, 3, 508.

9. Hayes, M. H. B.; Clapp, C. E.; Soil Sci. 2001, 164, 723.

10. Choudhry, G. G.; Humic Substances. Structural, Photophysical, Photochemical and Free Radical Aspects and Interactions with Environmental Chemicals, $1^{\text {st }}$ ed., Gordon and Breach Science Publishers: New York, 1984.

11. Cavani, L.; Ciavatta, C.; Trubetskaya, O. E.; Reznikova, O. I.; Afanas'eva, G. V.; Trubetskoj, O. A.; J. Chromatogr., A 2003, 983, 263.

12. Trubetskoj, O.; Reznikova, O. ; Eva, G. A.; Geoderma 1999, 93, 277.

13. Landgraf, M. D.; Silva, S. C.; Rezende, M. O. O.; Anal. Chim. Acta 1998, 368, 155.

14. Martin-Mousset, B.; Croue, J. P.; Lefebvre, E.; Legube, B.; Water Res. 1997, 31, 541.

15. Pacheco, M. L.; Havel, J.; Electrophoresis 2002, 23, 268.

16. Nórden, M.; Dabek-Zlotorzynska, E.; J. Chromatogr., A 1996, 739,421 .
17. Hosse, M.; Wilkinson, K.; J. Environ. Sci. Technol. 2001, 35, 4301.

18. Moraes, S. L.; Landgraf, M. D.; Rezende, M. O. O.; Eclet. Quim. 2004, 29, 47.

19. Pompe, S.; Heise, K.; Nitsche, H.; J. Chromatogr, A 1996, 723, 215 .

20. Fetsch, D.; Hradilová, M.; Méndez, E. M. P.; Havel, J.; J. Chromatogr., A 1998, 817, 313.

21. Schmitt-Kopplin, Ph.; Garrison, A. W.; Perdue, E. M.; Freitag, D.; Kettrup, A. J. Chromatogr., A 1998, 807, 101.

22. Schmitt-Kopplin, Ph.; Burhennen, J.; Freitag, D.; Spitellerkettrup, M. A.; J. Chromatogr., A 1999, 837, 253.

23. Peuravuori, J.; Lehtonen, T.; Lepane, V.; Pihlaja, K.; Talanta 2005, 67, 103.

24. Landgraf, M. D.; Javaroni, R. C.; Rezende, M. O. O.; J. Capillary Electrophor. 1998, 5, 193.

25. Pacheco, M. L.; Peña-Méndez, E. M.; Havel, J.; Chemosphere 2003, 51, 95.

26. Fetsch, D.; Havel, J.; J. Cromatogr., A 1998, 802, 189.

27. Altria, K. D. J. Cromatogr., A 1999, 856, 443.

28. Schnitzer, M.; Khan, S. U.; Soil Organic Matter, $1^{\text {st }}$ ed., Marcel Dekker: New York, 1978.

Received: October 25, 2006

Published on the web: January 14, 2008

FAPESP helped in meeting the publication costs of this article. 